\title{
O NADIR E 0 VI ENADIR: \\ trajetórias e apontamentos
}

\section{NADIR AND VI ENADIR: trajectories and notes}

NADIR Y VI ENADIR:

trayectorias y notas

Ana Lúcia Pastore Schritzmeyer Líder do Núcleo de Antropologia do Direito (NADIR)

Docente do Departamento de Antropologia e do Programa de Pós-Graduação em Antropologia Social da USP alps@usp.br

Brasil

Bruna Angotti

Vice-líder do Núcleo de Antropologia do Direito (NADIR) Docente da Faculdade de Direito da Universidade Presbiteriana Mackenzie angotti.bruna@gmail.com

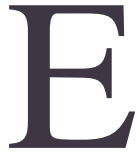

com muita alegria que apresentamos este conjunto de nove artigos representantes da variedade temática, metodológica e analítica contida nos 153 (cento e cinquenta e três) papers apresentados em 18 (dezoito) grupos de trabalho (GTs) do VI ENADIR - Encontro Nacional de Antropologia do Direito realizado entre 26 e 29 de agosto de 2019 no Conjunto Didático de Filosofia e Ciências Sociais da FFLCH-USP - Faculdade de

\footnotetext{
${ }^{1}$ Toda a programação do VI ENADIR se encontra em <https://enadir-2019.blogspot.com/>. Acesso em $13 \mathrm{dez}$. 2020 .
}

Filosofia, Letras e Ciências Humanas da Universidade de São Paulo' ${ }^{1}$.

Os ENADIR são eventos bianuais promovidos pelo NADIR - Núcleo de Antropologia do Direito. Apesar dos nomes quase idênticos, o núcleo e os encontros não se confundem, pois é a existência do NADIR, desde 2008, que permite a realização dos ENADIR, desde 2009, ainda 
que seja possível afirmar que eles se retroalimentam.

O NADIR foi assim nomeado, em 14 de março de 2008, tanto em razão de suas iniciais quanto em função de alguns significados da palavra. Além de, em português, ser um nome próprio comum de dois gêneros, em astronomia designa o ponto inferior da esfera celeste, indicando o que está abaixo dos pés de um observador do universo, o oposto ao zênite. Em hebraico e em árabe nadir significa raro. Como nomear é criar, o NADIR tenta ser um lugar não óbvio, embaixo, oposto e, por isso mesmo, raro para pensar as múltiplas interfaces existentes e possíveis entre antropologia e direito ${ }^{2}$.

A missão do Núcleo é acolher pesquisadores(as) que se encontram em diversos níveis de formação, da graduação ao pós-doutoramento, cujos temas de interesse transitam pela antropologia do direito, permitindo-lhes trocar ideias, incrementar leituras, enriquecer e desenvolver projetos, o que acaba por fortalecer a própria área que, no Brasil, se encontra em franca expansão.

Um dos principais objetivos do grupo é manter seus membros em contato frequente, razão pela qual há reuniões quinzenais, de março a junho e de agosto a

\footnotetext{
${ }^{2}$ O NADIR está cadastrado no Diretório dos Grupos de Pesquisa no Brasil, Lattes, podendo ser visitado em
}

dezembro, totalizando geralmente 18 por ano. Também são suas metas: a) fomentar a divulgação das pesquisas dos membros do grupo, estimulando sua apresentação em congressos e sua publicação em periódicos; b) estabelecer interlocuções e parcerias com colegas de outras instituições acadêmicas e jurídicas; c) promover os ENADIR, a fim de que um conjunto mais amplo de pesquisadores(as) estabeleçam e/ou mantenham contato.

As cinco principais linhas de pesquisa do NADIR são:

\section{Antropologia da jurisprudência e} de narrativas de violência. Nela são estudadas relações entre violência, autoridade e linguagem em discursos referentes a situações institucionais hierárquicas em que se configuram procedimentos de exclusão social. A partir da antropologia, da filosofia do direito e da teoria da narrativa, episódios narrados em textos e/ou imagens são analisados a fim de se perceber sua polissemia e como as posições institucionais envolvidas

http://dgp.cnpq.br/dgp/espelhogrupo/612586 . Acesso em: 13 dez. 2020. 
determinam e são determinadas por aspectos linguísticos (vocabulário, sintaxe, organização discursiva) e ideológicos.

\section{Antropologia e Direitos Humanos.}

O foco desta linha reside em tensões entre universalismo e relativismo cultural, percepções locais acerca de tratados internacionais, tanto do ponto de vista de setores estatais quanto de outros agentes e agências, bem como embates entre significados culturais envolvidos em conceitos como direitos, justiça e dignidade da pessoa humana.

\section{Demandas por reconhecimento de} direitos e acesso à justiça. A ênfase, nesta linha, se volta para trabalhos antropológicos que exploram mecanismos sociojurídicos de produção de diferenças por meio de categorias como gênero, raça/etnia, idade, poder socioeconômico e temáticas referentes à equidade, à regulamentação jurídica de identidades, de direitos coletivos e formas de acesso à justiça.

\section{Profissionais e profissões do} direito e dos sistemas de justiça. A partir de um prisma antropológico, são analisados perfis, trajetórias e atuações de pessoas que trabalham em profissões e espaços dos sistemas de justiça, tais como cartorários, membros das polícias, magistrados, membros do ministério público, de defensorias públicas, advogados, jurados etc.

\section{Sistemas de justiça criminal e} criminologia. Nesta linha se reúnem reflexões sobre o sistema de justiça criminal e o sistema voltado para crianças e adolescentes em conflito com a lei, com ênfase em trabalhos etnográficos que privilegiam discussões sobre violência policial, ritual judiciário, formas de institucionalização e gestão de conflitos, aplicação de penas, políticas de segurança pública e de medidas socioeducativas.

Desde o seu nascimento, o NADIR também realizou pesquisas coletivas, como as três edições de um projeto voltado a percepções que estudantes do ensino médio 
tinham de Direitos Humanos ${ }^{3}$. Em 2010 aconteceram as primeiras trocas com a Universidade de Ottawa, no Canadá, e com o LAJP - Laboratório de Antropologia Jurídica de Paris. Em 2011, o NADIR se associou ao NEV-USP - Núcleo de Estudos da Violência da Universidade de São Paulo - e executou o Projeto "Sujeitos, Discursos e Instituições", vigente até março de $2016^{4}$.

Em fevereiro de 2013, o NADIR e o LAJP tiveram aprovada sua parceria no Programa USP-COFECUB, vigente até dezembro de 2016, graças ao qual alguns(mas) pesquisadores(as) do NADIR viajaram anualmente à Paris e, em contrapartida, pesquisadores(as) de lá foram recebidos em São Paulo, inclusive para participar dos III e IV ENADIR.

Em 2017, uma parceria com o Instituto Pro Bono propiciou o desenvolvimento da pesquisa "Audiências de Custódia e Advocacia Pro Bono: reflexões a partir de etnografias de interações entre atores judiciais". Nesse ano, ocorreram novas trocas com a Universidade de Ottawa e foi oferecida, por pesquisadores(as) do NADIR, a primeira edição do curso de difusão "Métodos

\footnotetext{
3 "Direitos Humanos - Percepções dos alunos da Escola Estadual Antonio Adib Chammas (Santo André/ SP, 2009-2010)"; "Direitos Humanos - Percepções dos alunos da Escola Estadual Antônio Inácio Maciel (Taboão da Serra/ SP, 2011-2012)"; "Direitos Humanos - Percepções dos alunos da Escola de Aplicação da USP (São Paulo/ SP, 2012-2013)".
}

consensuais de administração de conflitos: introdução à mediação e à justiça restaurativa", voltado tanto para a comunidade USP quanto para o público externo. A segunda edição, intitulada "Práticas Consensuais de Gestão de Conflitos" ocorreu em 2018 e a terceira, "Formação inicial em métodos consensuais de gestão de conflitos”, em 2019.

Em 2020, depois de duas reuniões presenciais, outras 17 (dezessete) ocorreram remotamente, o que permitiu a membros não mais residentes na cidade de São Paulo voltarem a participar, bem como novos(as) pesquisadores(as), de diversos lugares do Brasil, acompanharem os debates, seja em tempo real, seja acessando, posteriormente, as reuniões gravadas. A equipe de frequentadoras(es) e colaboradoras(es) do NADIR tem se mantido, ao longo de seus quase 13 (treze) anos de existência, majoritariamente composta por pessoas do sexo feminino que já cursaram ou cursam uma pós-graduação, havendo um bom equilíbrio entre quem tem vínculo com a USP e quem trabalha ou estuda em outras instituições, assim como entre quem se titulou em ciências sociais/antropologia e quem se titulou em

\footnotetext{
4 Disponível em : http://ccint.fflch.usp.br/projetointerunidades-em-violencia-democracia-e-direitos-subprojeto-sujeitos-discursos-e https://nev.prp.usp.br/noticias/apresentacao-dosresultados-parciais-da-pesquisa-memorias-de-guardasuniversitariosas-da-usp/ . Acessos em: 13 dez. 2020.
} 
direito. Costumamos brincar que a "senha" para participar é ter feito, estar fazendo ou querer fazer alguma pesquisa em antropologia do direito.

Voltando aos ENADIR, vale destacar que as seis edições realizadas até 2019 receberam apoios da CAPES (Coordenação de Aperfeiçoamento de Pessoal de Nível Superior), do Departamento de Antropologia e do PPGAS (Programa de Pós-Graduação em Antropologia Social) da USP, sendo que o V ENADIR, em 2017, também foi financiado pelo $\mathrm{CNPq}$ (Conselho Nacional de Desenvolvimento Científico e Tecnológico). Em todas as edições se reuniram pesquisadores(as) das mais variadas regiões brasileiras apresentando em mesas redondas e em grupos de trabalho (GTs) pesquisas recém concluídas ou em andamento ${ }^{5}$.

No que se refere à pós-graduação, os ENADIR, além de, durante os dias dos encontros, colocarem em contato vários(as) antropólogos(as) do direito, incentivam pós-graduandos(as) a cursar disciplinas fora de seus programas e incrementam colaborações entre docentes, seja em bancas, seja em outros encontros e congressos ou ainda estimulando-os(as) a se integrarem em equipes interinstitucionais.

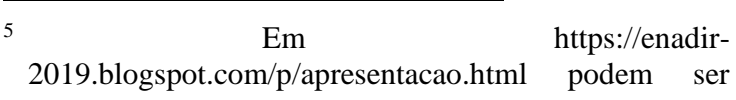

Como se poderá observar a partir da leitura dos trabalhos selecionados para este dossiê, uma das finalidades do VI ENADIR, seguindo a tradição das edições anteriores, foi produzir resultados qualitativamente significativos no interior da antropologia do direito, fazendo uma espécie de balanço nacional temático do "estado da arte". Vale ressaltar que uma primeira seleção dos trabalhos ora publicados se deu durante o próprio encontro, sob a responsabilidade das duplas de coordenadores(as) de cada GT. Posteriormente, ao se firmar a parceria com a Revista Abya Yala, cada texto selecionado passou por um novo crivo de dois pareceristas e por eventuais ajustes.

No artigo Da escuta à escrita: o fazer policial na construção de sujeitos e crimes em inquéritos policiais de violência contra a mulher, Ana Clara Klink de Melo reflete sobre a utilização das categorias "vítima", "autor" e "violência" em documentos policiais elaborados no espaço de uma Delegacia de Defesa da Mulher de São Paulo. Por meio de análise documental e de observação participante, a autora aponta como discursividades e moralidades de policiais envolvidos nos registros dos casos, em especial ao construírem perfis de vítimas, autores e testemunhas, resultam em diferentes narrativas de violências, moldando a maneira

acessadas as programações detalhadas de cada ENADIR. Acesso em: 13 dez. 2020. 
como os fatos são descritos na linguagem da lei. A pesquisa foi apresentada no grupo de trabalho (GT) As Práticas e as representações acionadas em audiências $e$ atos judiciais no sistema de justiça.

Renata Albuquerque, em seu artigo Consulta tramposa: interpretações sobre o direito entrecortadas pela política, analisa como lideranças indígenas bolivianas, de três povos diferentes, habitantes do Território Indígena e Parque Nacional Isiboro Sécure, avaliaram a consulta pública realizada pelo governo, em 2012, referente ao projeto que previa a construção de uma estrada no território. A mobilização de atores contrários e favoráveis ao projeto colocou o território indígena em lugar de destaque no debate político boliviano. A autora mostra como, no território, a consulta pública não foi vista como uma conquista, mas um ato de imposição de vontade de determinados grupos à comunidade. $\mathrm{O}$ texto foi originalmente apresentado no GT Consulta prévia, livre e informada $e$ protocolos próprios de consulta: experiências de autonomia política $e$ diálogo intercultural no Brasil.

A análise de uma prática de redução de danos entre pessoas em situação de rua na cidade de Franca é o foco da pesquisa apresentada por Larissa Soares de Melo, Murilo Gaspardo e Túlio Boso Fernandes dos Santos. No artigo Redução de danos e população de rua em Franca: cachimbos e latas, os(a) autores(a) relatam uma experiência em oficinas de cachimbo com usuários de crack, no âmbito do projeto de extensão "Núcleo de Cidadania Ativa". A construção de cachimbos permitiu que se trabalhassem questões como a autorregulação na relação entre indivíduo e substância, bem como a criação de vínculos entre profissionais e usuários, propiciando que temas referentes à saúde fossem tratados nos encontros. A pesquisa foi apresentada no GT Diálogos e experiências entre antropologia e direito nas formações jurídicas: clínicas, extensões, pesquisas coletivas e novas tecnologias de ensino $e$ difusão de direitos.

No artigo Como a seletividade racial gerada pela polícia contra jovens em conflito com a lei gera desigualdades em suas abordagens e apreensões?, Luana Barbosa da Silva e Marina de Oliveira Ribeiro se debruçam sobre abordagens policiais e apreensões de adolescentes na cidade de Campinas, estado de São Paulo. As autoras priorizam o marcador racial, de modo a trazer dados quantitativos e qualitativos à análise da seletividade penal. Para tanto, construíram um banco de dados com informações referentes à raça, sexo, socioespacialidade e escolaridade de adolescentes, policiais e curadores. Apresentam, dentre outros aspectos, uma 
análise do perfil dos jovens mais violentados pelas polícias na cidade: adolescentes do sexo masculino, pardos, com 17 (dezessete) anos e baixa escolaridade. As autoras mostram, por fim, como tais achados dialogam com outras pesquisas. $\mathrm{O}$ trabalho foi apresentado no GT Discussões de gênero, raça e classe no sistema de justiça criminal e juvenil.

O artigo de autoria de Paulo Victor Leite Lopes traz reflexões sobre o trabalho de campo que realizou em um serviço voltado ao atendimento de "homens autores de violência doméstica”. Denominado Aconselhamentos, bonificação $e$ compromissos: a gestão [precária] do possivel com homens autores de violência doméstica, o texto, ao abordar as relações de hierarquia e dominação entre os participantes e os administradores do espaço, apresenta uma reflexão sobre o Estado e as relações que produz. Os resultados da pesquisa foram apresentados no GT Gênero, sexualidade e direitos.

Carla Villalta e Aline Lopes Murillo assinam o artigo YO SOY...: o direito à identidade e os nomes dos netos das Abuelas de Plaza de Mayo na Argentina. Nesse texto, elas analisam leis de registro civil e os trâmites burocráticos voltados à revisão da identidade de netas e netos das Abuelas de la Plaza de Mayo, na Argentina, após tomarem conhecimento de quem foram seu pai e sua mãe biológicos vitimados pela ditadura. Analisam, igualmente, os sentidos de nomes e sobrenomes na construção da identidade dessas pessoas, refletindo sobre o papel dos documentos e da nominação na produção de memórias e na defesa de direitos. $\mathrm{O}$ trabalho foi apresentado no GT Interseções da antropologia com os direitos de crianças, adolescentes e jovens.

Em Comunidades quilombolas: discursos e disputas por direitos territoriais, Amanda Lacerda Jorge e André Augusto Pereira Brandão refletem a respeito de disputas interpretativas, no campo jurídico, pertinentes à titulação e à demarcação de territórios quilombolas. Ao se debruçarem sobre a Ação Direta de Inconstitucionalidade $n^{\circ} 3239 / 2004$, que questionou o processo de titulação dessas terras, a autora e o autor expõem o alto grau de conflitos interpretativos que permeou o julgamento finalizado em 2018, bem como evidenciam como tal debate pôs em xeque garantias e direitos fundamentais dos povos quilombolas. $\mathrm{O}$ texto original foi apresentado no GT Processos de reconhecimento de direitos, mediação intercultural e disputas territoriais no Brasil contemporâneo.

No artigo Hierarquia por todo lado: uma análise da hierarquia militar no espaço universitário e seus 
desdobramentos, Érika Ferreira e Perla Alves Bento de Oliveira Costa apresentam os resultados da observação participante que realizaram no âmbito do Curso de Tecnólogo em Segurança Pública e Social oferecido pela Universidade Federal Fluminense, voltado a profissionais da ativa na área de segurança pública do estado do Rio de Janeiro. No texto, as autoras refletem sobre questões e conflitos relacionados à hierarquia, considerando as distintas socializações militares e universitárias em choque no ambiente do curso. A pesquisa foi apresentada no GT Profissões jurídicas, rituais judiciários, sistema de justiça e pesquisa empírica em direito em diálogo com a antropologia.

Por fim, Andressa Siqueira, no artigo $A$ relação entre materialidade $e$ imaterialidade na salvaguarda dos patrimônios culturais imateriais: uma análise a partir da Roda de Capoeira, analisa a importância da conservação material do berimbau como essencial à salvaguarda da capoeira. Por meio de pesquisa documental e de observação participante, a autora mostra o quanto a escassez ou a dificuldade de acesso a bens naturais necessários à produção do berimbau podem representar riscos à salvaguarda do patrimônio imaterial que é a Roda de Capoeira. Nesse sentido, a autora defende o direito a bens naturais como garantia de bens imateriais. O trabalho foi apresentado no GT Salvaguarda do patrimônio cultural e dos direitos identitários.

Já na seção resenhas e ensaios deste dossiê, são apresentadas quatro obras, três das quais produzidas por pesquisadoras do NADIR e a quarta de autoria de uma colaboradora do Núcleo, sendo todos(as) os(as) resenhistas pós-graduandos(as) também integrantes do NADIR, sob a orientação de Ana Lúcia Pastore Schritzmeyer no PPGAS-USP.

A doutoranda Sara Vieira Antunes resenhou a segunda edição do livro Entre as Leis da Ciência, do Estado e de Deus: o surgimento dos presídios femininos no Brasil, de Bruna Angotti, publicada em 2018. O mestrando Filipe Novaes Pinto resenhou a obra Audiências de custodia: percepções morais sobre violência policial e quem é vítima, de Ana Luiza Villela de Viana Bandeira, publicada em 2020. Ambos os livros são frutos das dissertações de mestrado das autoras, defendidas no âmbito do PPGAS-USP sob a orientação de Ana Lúcia Pastore Schritzmeyer.

Já a obra $A$ verdade jurídica nos processos de tráfico de drogas, de Maria Gorete Marques de Jesus, pesquisadora do NEV-USP e colaboradora do NADIR, foi resenhada por Caroline Laya de Menezes e Pedro Roney Dias Ribeiro, ela mestranda e ele doutorando. Por fim, a obra coletiva $O$ 
gênero do direito - análise de práticas e instituições, organizada pela professora da Faculdade de Direito da UFMG (Universidade Federal de Minas Gerais) Camila Silva Nicácio, pesquisadora do NADIR, e por Júlia Silva Vidal, publicada em 2020, foi resenhada por Gabriela Perissinotto de Almeida, doutoranda do Programa de Pós-Graduação em Psicologia da UFSCar (Universidade Federal de São Carlos), co-orientada por Ana Lúcia Pastore Schritzmeyer no PPGAS-USP.

Para encerrar esta introdução, vale registrar que todos os textos já apresentados em GTs das seis edições do ENADIR estão disponíveis em anais ${ }^{6}$ e em algumas revistas (acessadas em 20/12/2020):

\section{ENADIR}

Revista de Antropologia, USP, v. 53, n. 2, 2010. "Dossiê Antropologia do Direito". Disponível em: http://www.revistas.usp.br/ra/issue/ view/3089

\section{ENADIR}

Revista Cadernos de Campo, USP, v.22, n.22, 2013. "Caderno Especial". Disponível em: http://www.revistas.usp.br/cadernos decampo/issue/view/4181

\section{ENADIR}

Confluências. Revista Interdisciplinar de Sociologia e Direito, v. 17, n.3, 2015. "Dossiê" https://periodicos.uff.br/confluencia s/issue/view/1805

Revista Euroamericana de Antropología, n.2, Junio, 2016. "Dosier Antropología del Derecho en Brasil". Disponível em: https://iiacyl.files.wordpress.com/2 016/07/portada-inicial.pdf e https://iiacyl.wordpress.com/rea/nu meros/

\section{$V$ ENADIR}

REED - Revista de Estudos Empíricos em Direito, v.5, n. 3, 2018. "Suplemento Especial - V Encontro Nacional de Antropologia do Direito". Disponível em: https://reedrevista.org/reed/issue/vi ew/13

\section{ENADIR}

REED - Revista de Estudos Empíricos em Direito, v. 7 n. 2, 2020. "Dossiê Etnografias sobre justiça e criminalidade em perspectiva". Disponível em: https://reedrevista.org/reed/issue/vi ew/19

Disponível em : <http://nadir.fflch.usp.br/anaisencontro-nacional-de-antropologia-do-direito-issn2595-8194-0 >. Acesso em : 13 dez. 2020. 
Em nome do NADIR, agradecemos imensamente à equipe da Abya Yala, em especial às colegas Rebecca Lemos Igreja e Talita Rampin, da UnB (Universidade de Brasília), pela receptividade à nossa proposta deste dossiê e pelo cuidado ao compô-lo, inclusive no que se refere à capa, que retrata um momento especialmente potente do VI ENADIR: a apresentação da peça “(In)justiça”, encenada pelo Grupo de Teatro Heliópolis ${ }^{7}$.

Que, com esta parceria, estreitemos ainda mais os laços entre a Revista Abya Yala/ UnB e o NADIR/ USP. Boa leitura a todas(os)!

\section{Ana Lúcia Pastore Schritzmeyer}

alps@usp.br

Líder do NADIR

Docente do Departamento de Antropologia e do Programa de Pós-Graduação em

Antropologia Social da

Universidade de São Paulo

\section{Bruna Angotti}

angotti.bruna@gmail.com

Vice-líder do NADIR

Docente da Faculdade de Direito da Universidade Presbiteriana Mackenzie

São Paulo, dezembro de 2020.

\footnotetext{
${ }^{7}$ Todos os detalhes estão disponíveis em: $<$ https://enadir-
} 